\title{
Phytoextraction of Cadmium from Contaminated Soil Assisted By Microbial Biopolymers
}

\author{
Jian PU* and Kensuke Fukushi
}

Integrated Research System for Sustainability Science, The University of Tokyo, Japan

\begin{abstract}
Heavy metal contaminated soils remain as a challenging and essential task for environmental engineering Phytoremediation (plant-based remediation) is effective for the mitigation of large area surface soil contamination, but needs long time and the efficiency is not high. Chemical agents could increase heavy metal bioavailability in soil and bring greater accumulation in plants, but also pose risks to soil, plant growth and ground water environment. In this study, microbial biopolymers, mainly composed of protein and polysaccharide, were obtained from non-induced, copper-induced and cadmium-induced activated sludge culture, and named as ASBP, ASBPCu and ASBPCd, respectively. The influence of microbial biopolymers on phytoextraction of cadmium in contaminated soil was investigated. Microbial biopolymers, compared to other agents, were found to be more effective in improving the phytoextraction of cadmium from soil. In ASBP, ASBPCu and ASBPCd, the cadmium content in plants was found to be 1.52, 1.63 and $1.33 \mu \mathrm{g}(1.9,2.0$ and 1.6 times of the control), respectively. It was also found that in the presence of microbial biopolymers ASBP, ASBPCu and ASBPCd, $10.9 \%, 26.2 \%$ and $13.7 \%$ of exchangeable cadmium fraction was extracted from soil matrix to plant or liquid, higher than the control test (4.3\%). Microbial biopolymers were more effective in improving cadmium accumulation in plants than other chemical agents. Owing to the benign nature, ease of production, and cadmium binding feasibility, microbial biopolymers may find utility as a new environmentally safe extracting agent for improving phytoextraction of cadmium from contaminated soil.
\end{abstract}

Keywords: Microbial biopolymers; Phytoextraction; Soil; Heavy metal; Cadmium

\section{Introduction}

Heavy metals contamination in soil is of major concern for both developed and developing countries, because of its potential toxicity and high persistence in the environment. The toxic metals, including copper, lead, cadmium, mercury, gold, and so on, are those that will displace essential metal ions in biological processes [1]. They affect crop yields, soil biomass and fertility, contributing to bioaccumulation in the food chain, eventually accumulating in human bodies and generating serious health threat to human and animals [2]. Over the course of recent decades, industrial and agricultural activities have accelerated dramatically metal pollution in different environmental compartments, especially in soil [3]. In soil samples collected up to $20 \mathrm{~km}$ in each direction from the Kabwe mine, the cadmium concentration ranged between 0.08 and $28 \mathrm{mg} / \mathrm{kg}$ for only the fractions of metals extractable by $0.5 \mathrm{M}$ nitric acid and that could be available for plant uptake in the environment [4]. In 2004, one study in Japan estimated that an arable land area of 7327 hectares $(0.16 \%$ of the total arable land) was polluted by heavy metals ( $\mathrm{Cd}, \mathrm{Cu}$ and/or $\mathrm{As})$, in which cadmium contamination was observed across $92.6 \%$ of land [5]. Various in situ and ex situ remediation methods have been employed for restoration of soils contaminated with heavy metals, including physical/chemical/ biological techniques [6,7]. Phytoremediation has attracted much attention because it is environmental friendly and relatively cheap. Phytoremediation uses plants to extract, sequester and/or detoxify heavy metals and other pollutants, and/or accumulate in different parts of them $[8,9]$. Phytoextraction is the removal of metals from water and soil and concentration into plants parts [10-13]. It usually needs long time and the efficiency is not high. Moreover, a large proportion of metal contaminants are unavailable for root uptake by plants. Thus extracting agents were applied to improve phytoextraction of heavy metals from contaminated soil [14]. When Ethylenediaminetetraacetic acid (EDTA) was added to soil, it forms soluble complexes with metals from soil, mainly from the exchangeable fraction, organic matter and carbonate-bound fractions [15]. Despite of the stimulation of heavy metal accumulation in plants, the addition of chemicals as extracting agents can also inhibit the uptake of some major elements for plants and pose an additional threat of soil quality and groundwater. Therefore, natural agents seem to be more promising because they are economically acceptable and environmentally benign. Researchers suggested that biomass from biological pollution control processes, especially from activated sludge systems, could be effective in removing heavy metals from polluted waters [16,17]. The activated-sludge bacteria produce extracellular biopolymers to protect themselves from the outer environment with heavy metals [18-20]. Microbial biopolymers produced by bacteria are composed of polysaccharides, proteins, nucleic acids, etc. In many studies, proteins were found to be the main component with a 4 to 5 protein/carbohydrate ratio [2123]. The proteinaceous biopolymers are considered to be economical and were reported to play an important role in removing heavy metals from aqueous solution [16]. In the other hand, plants release root exudates (eg. amino acid) containing biopolymers with the potential to enhance cadmium uptake, translocation and resistance [24]. However, the concentration of the naturally excreted biopolymers is low. In this paper, high concentration of microbial biopolymers would be produced and used for cadmium removal by plant from contaminated soil. We demonstrate the feasibility of using microbial biopolymers to enhance

*Corresponding author: Jian PU, Integrated Research System for Sustainability Science, The University of Tokyo, Japan, E-mail: pu@ir3s.u tokyo.ac.jp

Received May 27, 2013; Accepted May 29, 2013; Published July 20, 2013

Citation: Jian PU, Fukushi K (2013) Phytoextraction of Cadmium from Contaminated Soil Assisted By Microbial Biopolymers. Agrotechnol 2: 110. doi:10.4172/2168-9881.1000110

Copyright: ( 2013 Jian PU, et al. This is an open-access article distributed unde the terms of the Creative Commons Attribution License, which permits unrestricted use, distribution, and reproduction in any medium, provided the original author and source are credited. 
the removal of cadmium from contaminated soil by phytoextraction. The results presented here may pave the way for the use of microbial biopolymers in phytoextraction of heavy metals in contaminated soils.

\section{Experimental Methods}

\section{Soil characterization and preparation}

The black soil $\left(\mathrm{pH}\left(\mathrm{H}_{2} \mathrm{O}\right)=5.0, \mathrm{pH}(\mathrm{KCl})=4.5, \mathrm{TC}=146.4 \mathrm{~g} / \mathrm{kg}\right)$ is a widely used garden soil in Japan. The black soil was artificially contaminated by soaking autoclaved soil in cadmium nitrate solution at neutral $\mathrm{pH}$ condition. Soil samples were then rinsed recovered and dried until the weight was reduced to less than 5\%. Dried cadmiumcontaminated soil sample was then stored in a closed plastic container for experimental use.

\section{Plant for phytoextraction}

In the genus of Crassula, Crassula helmsii was reported to be a Cuaccumulator [25], and Crassula portulacea was found to have great efficiency to remove benzene from air. Moreover, Crassula alba was recorded to be a local indicator and hyperaccumulator for cobalt $(>1000$ $\mu \mathrm{g} / \mathrm{g}$ dry mass). Referring to the accumulation ability of Crassula family for pollutants, Crassula lycopodioides v. pseudolycopodioides was used in this study, in order to investigate the overall uptake of cadmium by the plant.

\section{Activated sludge cultivation}

A sludge seed of MLSS about $4.2 \mathrm{~g} / \mathrm{l}$ from water treatment plant was used for cultivation. The batch reactors were fed with different synthetic media: Non-selective medium (NSM); Feed 1: NSM with $2 \mathrm{mg} / \mathrm{l}$ copper as inducer; Feed 2: NSM with $2 \mathrm{mg} / \mathrm{l} \mathrm{cadmium}$ as inducer. Seed sludge was introduced into different culture media initially, and cultivated at $120 \mathrm{rpm}$ in $25^{\circ} \mathrm{C}$ thermostat for $24 \mathrm{~h}$. After that, the 1 st generation was harvested and $1 \mathrm{ml}$ mixture was introduced to a series of fresh media for cultivating next generation. To ensure stable composition of the bacterial fauna, this sub-culture process was carried out for several times in the fresh media, generally, for $24 \mathrm{~h}$. Finally, the media were collected as the resource of biopolymer extraction.

\section{Preparation of water-soluble biopolymers}

Sonication, detergent and freeze-thaw were used to obtain a full disruption of cells in cultivated sludge. Each culture liquid was centrifuged $\left(10,000 \mathrm{~g}, 5 \mathrm{~min}, 4^{\circ} \mathrm{C}\right)$ and washed with water prior to extraction. The pellet was re-suspended in $20 \mathrm{mM}$ Tris- $\mathrm{HCl}$ buffer $(\mathrm{pH}=8)$. Lysozyme was added to reach $0.4 \mathrm{mg} \mathrm{ml}-1$ and incubate for $20 \mathrm{~min}$. Then, the sludge suspension then went through freeze-thaw for 3 cycles at $-80^{\circ} \mathrm{C}$ and $30^{\circ} \mathrm{C}$, respectively. The suspension was sonicated for $15 \mathrm{~min}$ with $50 \%$ burst at $170 \mathrm{~W}, 20 \mathrm{kHz}$. The tubes containing the samples were kept in crushed ice during sonication. After that, the cell mass suspensions were centrifugated at $10,000 \mathrm{~g}$ for $30 \mathrm{~min}$ at $4^{\circ} \mathrm{C}$. Supernatants were collected and filtered through $0.45 \mu \mathrm{m}$ membrane. The filtrates containing water-soluble biopolymers were used for following tests. The water-soluble biopolymers extracted from modified activated sludge were named "Activated Sludge Bio-Polymers" (ASBP), ASBPCu and ASBPCd. ASBP was derived using Non-Selective Media (NSM) as the control, ASBPCu was from NSM with trace copper as biopolymer inducer, and ASBPCd was from NSM with trace cadmium as biopolymer inducer. Lowry method [26] was used for protein quantification, with Bovine Albumin Serum (BSA) as standard.

\section{Measurement analysis of biopolymers}

An ultra filtration device was used to separate the biopolymer-bound cadmium from aqueous solution and determine the concentrations of cadmium complex formed in the aqueous biopolymers. The mixed liquor was introduced to $3 \mathrm{kDa}$ cut-off using Amicon ultra- $43 \mathrm{~K}$ device (Millipore) and washed with $1 \mathrm{mM}$ PBS buffer for 3 times. Subsequent determination of the metal content in the filtrate was carried out by FAAS.

\section{Microbial biopolymers-cadmium extraction studies}

Batch experiments were carried out using $1 \mathrm{~g}$ of soil with a soilsolution $(\mathrm{w} / \mathrm{v})$ ratio of $1: 5$ at different $\mathrm{pH}$ condition. Low and high concentrations of extracting agents (including EDTA, citric acid and biopolymer solutions) were added to the contaminated soil and vigorously mixed with a mechanical shaker at $40 \mathrm{rpm}$ for 24 hours. The $\mathrm{pH}$ value in the mixture of soil and extracting solutions were adjusted using $\mathrm{HNO}_{3}$ or $\mathrm{NaOH}$. The concentrations of proteins in biopolymers, used for cadmium extraction, were determined before and after its application in soil. Moreover, after the extraction, the biopolymers were separated by ultra filtration with a cut-off at $3 \mathrm{kDa}$. The Cadmium concentration and protein concentrations in both fractions (with a $\mathrm{MW}>3 \mathrm{kDa}$ and $<3 \mathrm{kDa}$ ) were determined. Comparative experiments were carried out using different concentrations of EDTA $(0.005 \mathrm{mM}$, $0.05 \mathrm{mM}$ and $1 \mathrm{mM}$ ) and $1 \mathrm{mM}$ of citric acid. Water was used as the control.

\section{Effects of biopolymers in phytoextraction of cadmium from} soil

The soil was planted with Crassula lycopodioides $v$. pseudolycopodioides in test tubes. The soil sample (14.9 mg Cd/kg dried soil) was submerged in an aqueous solution of biopolymers (ASBP, ASBPCu and ASBPCd) and other agents (BSA, EDTA, and citric acid) to ensure a uniform contact between agents and soil matrix. EDTA concentrations were $5.0 \times 10^{-3} \mathrm{mM}$ and $0.4 \mathrm{mM}$. The concentration of citric acid and BSA was $1.7 \mathrm{mM}$ and $3.0 \times 10^{-2} \mathrm{mM}$, respectively. The biopolymers used were 2493,2350 , and $2768 \mu \mathrm{g} / \mathrm{ml}\left(8.3 \times 10^{-2}, 7.8 \times 10^{-2}\right.$, and $9.2 \times 10^{-2} \mathrm{mM}$ ) for ASBP, ASBPCu and ASBPCd, respectively. The tubes without chelating agents and those without cadmium were set as control. Five replicates of test tubes, each contained one plant, were used for one batch of experiment. The plants were incubated at $25^{\circ} \mathrm{C}$ with a $12 \mathrm{~h}$ photoperiod in the greenhouse, with pump aeration once a day. Nutrient medium was added regularly to maintain the constant water level. After 3 weeks of incubation, the plant as well as soil samples were collected from the solution. Both protein and cadmium concentrations were determined in the aqueous phase of solutions. The cadmium concentration in plant was analyzed with FAAS after microwave digestion. The soil samples were analyzed for cadmium species, using a modified sequential extraction method.

\section{Results and Discussion}

\section{Characteristics of biopolymers}

The molecular weight (MW) of activated sludge biopolymers was analyzed by sodium dodecyl sulfate polyacrylamide gel electrophoresis (SDS-PAGE) with Coomassie brilliant blue (CBB) R250 staining, see Figure 1. A broad range of MW was found in ASBP, as summarized in Table 1. About $21.4 \%, 18.7 \%$ and $20.6 \%$ had MW over $50 \mathrm{kDa}(3.9 \%$, $3.1 \%$ and $3.1 \%$ over $100 \mathrm{kDa}$ ) and $10.5 \%, 7.9 \%$ and $7.6 \%$ below $5 \mathrm{kDa}$, for ASBP, ASBPCu and ASBPCd, respectively. The mean MW was 31 $\mathrm{kDa}, 30 \mathrm{kDa}$ and $31 \mathrm{kDa}$ for ASBP, ASBPCu and ASBPCd, respectively. The results of MW distribution obtained by this measurement were considerably lower than the $200 \mathrm{kDa}$ reported for extracellular 
Citation: Jian PU, Fukushi K (2013) Phytoextraction of Cadmium from Contaminated Soil Assisted By Microbial Biopolymers. Agrotechnol 2: 110. doi:10.4172/2168-9881.1000110

Page 3 of 5

\section{$\operatorname{BSA}(\mu \mathrm{g})$}

$\begin{array}{lllllllllllll}M & 1 & 2 & 3 & 4 & 5 & 6 & 0.1 & 0.2 & 0.5 & 1.0 & 2.0\end{array}$

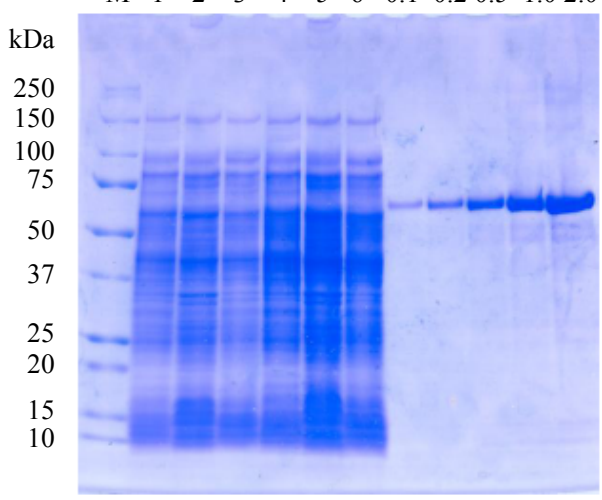

Figure 1: ASBP analysis by sodium dodecyl sulfate polyacrylamide gel electrophoresis (SDS-PAGE) with Coomassie brilliant blue (CBB) R250 staining. (Lane $\mathrm{M}$ : precision plus all blue standards; 1: activated sludge biopolymer (ASBP); 2: ASBPCu; 3: ASBPCd; 4: ASBP>3 kDa part; 5: ASBPCu $>3 \mathrm{kDa}$ part; 6: ASBPCd $>3 \mathrm{kDa}$ part. Standard BAS was used in other lanes).

\begin{tabular}{|c|c|c|c|}
\hline $\begin{array}{c}\text { Molecular weight } \\
(\mathbf{k D a})\end{array}$ & \multicolumn{3}{|c|}{ Fraction (\%) } \\
\cline { 2 - 4 } & ASBP & ASBPCu & ASBPCd \\
\hline$<3$ & 10.0 & 7.7 & 7.4 \\
\hline $3 \sim 5$ & 0.5 & 0.2 & 0.2 \\
\hline $5 \sim 10$ & 8.6 & 6.8 & 6.7 \\
\hline $10 \sim 20$ & 38.4 & 41.4 & 38.8 \\
\hline $20 \sim 30$ & 8.6 & 11.5 & 11.4 \\
\hline $30 \sim 40$ & 6.0 & 7.2 & 8.5 \\
\hline $40 \sim 50$ & 6.4 & 6.5 & 6.4 \\
\hline $50 \sim 60$ & 8.4 & 6.2 & 8.2 \\
\hline $60 \sim 80$ & 3.7 & 4.0 & 3.3 \\
\hline $80 \sim 100$ & 5.4 & 5.4 & 6.0 \\
\hline$>100$ & 3.9 & 3.1 & 3.1 \\
\hline Mean MW & $31 \mathrm{kDa}$ & $30 \mathrm{kDa}$ & $31 \mathrm{kDa}$ \\
\hline
\end{tabular}

Table 1: Molecular weight distribution of activated sludge biopolymers. MW fraction was calculated based on the band intensity of each protein band of CBB-stained SDS-PAGE gel.

polymeric substances extracted from activated sludge by physical treatment followed by removal of low MW solutes lower than $1 \mathrm{kDa}$ [27] (Figure 1) (Table 1).

\section{Interactions of microbial biopolymers with cadmium in soil solution}

Ccadmium uptake of biopolymers in soil solution was shown in Figure 2. For the Cd-biopolymer binding part remained in extracts, ASBPCd showed slightly higher Cd uptake than ASBP and ASBPCu (Figure 2).

The polymer-metal ion interaction might be intra and/or interchain. Intra-chain appeared to be the most common for a numerous group of polymer metal binding, which showed comparatively high chemical and thermal stability. Another specific feature of these compounds would be the total saturation of the coordination sphere of the transition metal ion. The polymer interacted with metal ion by binding functional groups of two different macromolecules, which supplied "acidic" functional groups and "basic" groups, respectively. Thus, the process of metal binding with mixed biopolymers would have promising application with regards to biological reactions [28]. The variables that might affect the polymer-metal ion interactions were intrinsic to the polymer: nature of atoms in the backbone chain, nature of the functional groups attached to the backbone, structure and copolymer composition, molecular weight and polydispersity, distance between functional groups and backbone, degree of branching, etc.; other variables might be extrinsic to the polymer: for example $\mathrm{pH}$, ionic strength, nature and charge of the metal ions, temperature, or nature of the counterion of the metal ion [28]. The sorption of cadmium by microbial biopolymers was significantly lower than cadmium sorption in solution. This difference could be due to the missing of important proteins from solution to solid surface, with or without heavy metal bound with them. In this study, up to $36-60 \%$ of protein in ASBP, ASBPCu and ASBPCd was found to be adsorbed onto soil matrix. In the extracts of biopolymers, TOC concentration was reduced to $11-37 \%$ of the original.

\section{Effects of microbial biopolymers in phytoextraction of cadmium from soil}

Eight sets of experiments were simultaneously assayed: only plant in soil (no agent added), plants in soil supplemented with (i) biopolymers (ASBP, ASBPCu, and ASBPCd), (ii) two different concentrations of EDTA, (iii) citric acid, (iv) BSA. As shown in Figure 3, while biopolymers (ASBP, ASBPCu and ASBPCd) were used, the metal concentrations in the plant biomass were found to be 2.03, 1.70 , and 1.74 times as high as the control plants, respectively. The concentration of cadmium in plant biomass was found to be 0.62 1.56 times, 1.22 times, and 1.33 times as high as the control, in the presence of EDTA, citric acid, and BSA, respectively. The plant uptake of cadmium from contaminated soil was reduced only in presence of

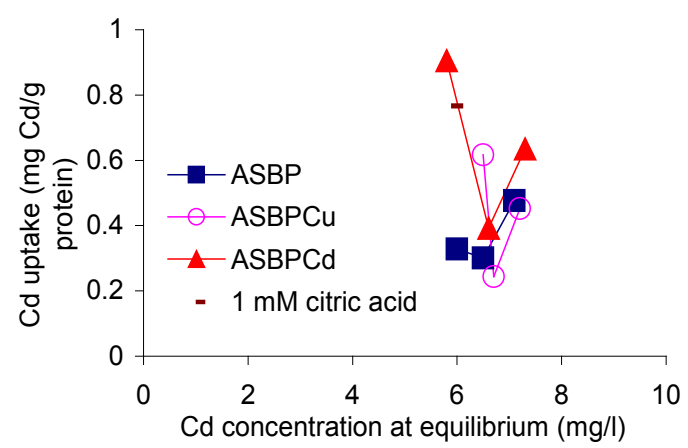

Figure 2: Uptake of cadmium from soil using biopolymers (MW $>3 \mathrm{kDa})$. The $\mathrm{x}$-axis shows cadmium concentration in the soil solution at equilibrium.

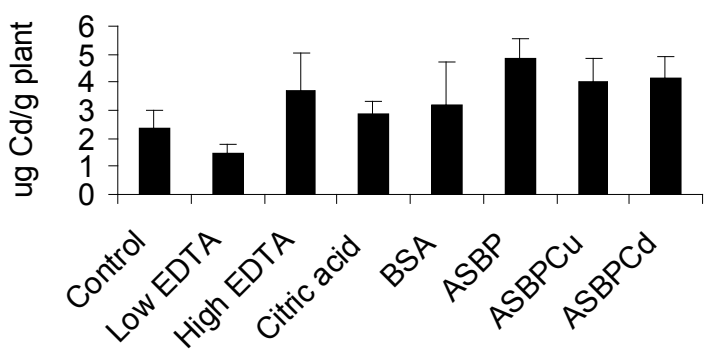

Figure 3: Cadmium concentration in plant biomass. Error bars represented standard deviations for five replicate experiments. 


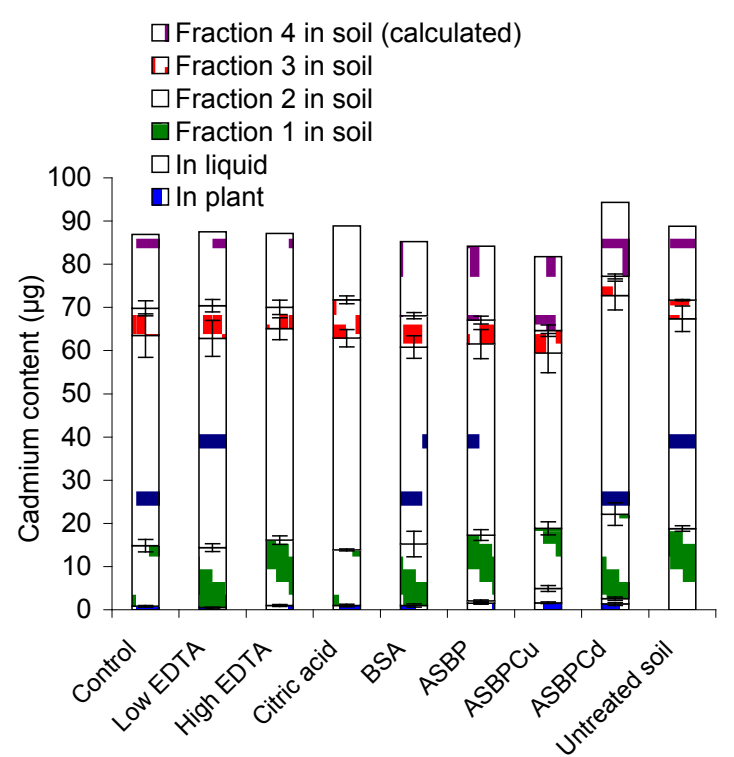

Figure 4: Cadmium distribution in plant, liquid and soil fractions after phytoextraction of cadmium from $6 \mathrm{~g}$ contaminated soils using biopolymers and other extracting agents (EDTA, citric acid, BSA). Water was used as the control. For cadmium fractions in soil, fraction 1: exchangeable + water and acid-soluble; fraction 2: Iron and manganese oxides; fraction 3: Organic matter and sulfides; fraction 4: residual. Cadmium contents in fraction 4 were under detection line in this experiment. Control represented the sequential extraction of cadmium from untreated soil (total cadmium concentration: $14.9 \mathrm{mg} \mathrm{Cd} / \mathrm{kg}$ dried soil). Error bars represented standard deviations for five replicate experiments.

EDTA at concentration of $5 \times 10^{-6} \mathrm{M}$ (Figure- 3 ). The stability constant for EDTA-Cd (16.5) was substantially higher than BSA $(\operatorname{logK}=3.6)$ and ASBP-Cd $(\operatorname{logK}=3.7)$. One study reported that the EDDS was found more efficient in $\mathrm{Pb}$ uptake by $C$. sativa, although the stability constant for EDTA-Pb was significantly higher than EDDS-Pb [29]. LogK value was not deemed enough to represent the potency of specific chelating agents for enhanced phytoextraction. The overall efficiency of agents for aiding phytoextraction was considered to be plant-specific, as well as being controlled by the stability constant and soil conditions.

\section{Mobilization of cadmium from soil using biopolymers during phytoextraction}

Sequential extraction of soil cadmium was performed after phytoextraction with biopolymers (ASBP, ASBPCu and ASBPCd) and other agents (water, EDTA, citric acid and BSA), as shown in Figure 4. The existence of biopolymers allowed higher cadmium content accumulated in plant biomass, than other extracting agents. In ASBP, ASBPCu and ASBPCd, the cadmium content in plants was found to be $1.52,1.63$ and $1.33 \mu \mathrm{g}(1.9,2.0$ and 1.6 times of the control), respectively. In phytoextraction of Low EDTA, High EDTA, Citric acid and BSA, the cadmium content in plants was found to be $0.50,0.97$, 0.99 and $0.98 \mu \mathrm{g}(0.6,1.2,1.2$ and 1.2 times of the control), respectively. In phytoextraction together with biopolymers (ASBP, ASBPCu and ASBPCd), cadmium content was found to be $0.52,3.31$ and $1.24 \mu \mathrm{g}$ in $9 \mathrm{ml}$ liquid, respectively. Biopolymers solubilized cadmium from soil to liquid. However, cadmium was not detected in condition with other extracting agents. Cadmium in liquid would give an easier uptake by plants, if compared with cadmium fractions in soil (Figure 4).

The exchangeable fraction of heavy metals in the soil is the fraction that could interact with biological targets and pose a health risk to human via food chain contamination. Thus, this research of phytoextraction focused on removal of exchangeable fractions of cadmium from contaminated soil by plant. In the phytoextraction of cadmium from contaminated soil, it was found that $10.9 \%, 26.2 \%$ and $13.7 \%$ of exchangeable cadmium fraction was extracted from soil matrix to plant or liquid, higher than the control test (4.3\%). Microbial biopolymers were effective in improving the available cadmium amount in the soil, thus providing a higher and sub sequential potential of cadmium uptake by plants in long term phytoextraction.

\section{Conclusion}

This paper elucidated cadmium binding characteristics of microbial biopolymers and a sorption of cadmium was observed by microbial biopolymers both in solution and in soil. With the existence of microbial biopolymers, the cadmium uptake by phytoextraction from the contaminated soil increased. In this paper, 10.9\%, 26.2\% and $13.7 \%$ of exchangeable cadmium fraction was extracted from soil matrix to plant or liquid, higher than the control test (4.3\%), when biopolymers were applied to phytoextraction of cadmium from contaminated soil. Microbial biopolymers, acting as a new environmental mobilizing agent, were more effective in improving cadmium accumulation in plants than other chemical agents. Instead of the current chemical agents, microbial biopolymers could significantly reduce the production costs.

\section{References}

1. Hughes MN, Poole R K (1991) Metal speciation and microbial growth - the hard (and soft) facts. Journal of General Microbiology 137: 725-734.

2. Lao UL, Chen A, Matsumoto MR, Mulchandani A, Chen W (2007) Cadmium removal from contaminated soil by thermally responsive elastin (ELPEC20) biopolymers. Biotechnol Bioeng 98: 349-355.

3. Gupta SK, Herren T (2000) Wenger K, Krebs R and Hari T In situ gentle remediation measures for heavy metal-polluted soils. In Terry $N$ and Banuelos G (ed.) Phytoremediation of Contaminated Soil and Water. USA: CRC Press LLC. 303-322.

4. Tembo BD, Sichilongo K, Cernak J (2006) Distribution of copper, lead, cadmium and zinc concentrations in soils around Kabwe town in Zambia. Chemosphere 63: 497-501.

5. Kikuchi T, Okazaki M, Toyota K, Motobayashi T, Kato M (2007) The input-output balance of cadmium in a paddy field of Tokyo. Chemosphere 67: 920-927.

6. Makino T, Kamiya T, Takano H, Itou T, Sekiya N, et al. (2007) Remediation of cadmium-contaminated paddy soils by washing with calcium chloride: Verification of on-site washing. Environ Pollut 147: 112-119.

7. Patel MJ, Patel JN, Subramanian RB (2005) Effect of cadmium on growth and the activity of $\mathrm{H} 2 \mathrm{O} 2$ scavenging enzymes in Colocassia esculentum. Plant and Soil 273: 183-188.

8. Bizily SP, Rugh CL, Summers AO, Meagher RB (1999) Phytoremediation of methylmercury pollution: merB expression in Arabidopsis thaliana confers resistance to organomercurials. Proceedings of the National Academy of Sciences 96: 6808-6813.

9. Meagher RB, Rugh CL, Kandasamy MK, Gragson G, Wang NJ (2000) Engineered phytoremediation of mercury pollution in soil and water using bacterial genes In Terry N, Banuelos G (Edn.) Phytoremediation of Contaminated Soil and Water. USA: CRC Press LLC. 201-219.

10. Cunningham SD, Berti WR (2000) Phytoextraction and phytostabilization technical, economic, and regulatory considerations of the soil-lead issue. In Terry N, Banuelos G (Edn.) Phytoremediation of Contaminated Soil and Water. USA: CRC Press LLC, 359-376.

11. Pulford ID, Watson C (2003) Phytoremediation of heavy metal-contaminated land by trees-a review. Environment International 29: 529-540.

12. Ghosh M, Singh AP (2005) A review on phytoremediation of heavy metals and utilization of its byproducts. Applied Ecology and Environmental Research 3 1-18. 
Citation: Jian PU, Fukushi K (2013) Phytoextraction of Cadmium from Contaminated Soil Assisted By Microbial Biopolymers. Agrotechnol 2: 110. doi:10.4172/2168-9881.1000110

Page 5 of 5

13. Chen TB, Liao XY, Huang ZC, Lei M, Li WX, et al. (2007) Phytoremediation of arsenic-contaminated soil in China. In Willey $\mathrm{N}$ (Edn.) Phytoremediation: methods and reviews. Humana Press USA: 393-404

14. Wu LH, Luo LM, Xing XR, Christie P (2004) EDTA-enhanced phytoremediation of heavy metal contaminated soil with Indian mustard and associated potential leaching risk. Agriculture, Ecosystems and Environment 102: 307-318.

15. Wu LH, Luo YM, Song J (2007) In: Willey N Manipulating soil metal availability using EDTA and low-molecular weight organic acids. (Edn.) Phytoremediation: methods and reviews. Humana Press USA: 291-303.

16. Fukushi K, Chang D and Ghosh S (1996) Enhanced heavy metal uptake by activated sludge cultures grown in the presence of biopolymer stimulators. Water Science and Technology 34: 267-272.

17. Arican B, Gokcay CF, Yetis U (2002) Mechanistics of nickel sorption by activated sludge. Process Biochemistry 37: 1307-1315.

18. Kellems BL, Lion LW (1989) Effect of bacterial exopolymer on lead (II) adsorption by YAl2O3 in seawater. Estuarine, Coastal and Shelf Science 28: 443-457

19. Chen JH, Czajka DR, Lion LW, Shuler ML, Ghiorse WC (1995) Trace metal mobilization in soil by bacterial polymers. Environ Health Perspectives 103: 53-58

20. Chen JH, Lion LW, Ghiorse WC, Shuler ML (1995) Mobilization of adsorbed cadmium and lead in aquifer material by bacterial extracellular polymers. Water Research 29: 421-430.
21. Goodwin JAS, Forster CF (1985) A further examination into the composition of activated sludge surfaces in relation to their settlement characteristics. Water Resource 19: 527-533.

22. Fang HHP, Jia XS (1996) Extraction of extracellular polymer from anaerobic sludges. Biotechnology Techniques 10: 803-808

23. Liao BQ, Allen DG, Droppo IG, Leppard GG, Liss SN (2001) Surface properties of sludge and their role in bioflocculation and settleability. Water Res 35: 339350.

24. Clemens S, Palmgren MG, Kramer U (2002) A long way ahead: understanding and engineering plant metal accumulation. Trends in Plant Sci 7: 309-315.

25. Küpper H, Götz B, Mijovilovich A, Küpper FC, Meyer-Klaucke W (2009) Complexation and toxicity of copper in higher plants. I. Characterization of copper accumulation, speciation, and toxicity in Crassula helmsii as a new copper accumulator. Plant Physiology 151: 702-714.

26. Lowry OH, Rosebrough NJ, Farr AL, Randall RJ (1951) Protein measurement with the folin phenol reagent. J Biol Chem 193: 265-275.

27. Liu Y, Lam MC, Fang HH (2001) Adsorption of heavy metals by EPS of activated sludge. Water Sci Technol 43: 59-66.

28. Rivas BL, Pereira ED, Villoslada IM (2003) Water-soluble polymer-metal ion interactions. Progress in Polymer Science 28: 173-208.

29. Lestan D (2006) Enhanced heavy metal phytoextraction. In Mackova M Dowling D, Macek T Phytoremediation and Rhizoremediation (Edn). The Netherlands: Springer 115-132. 